Published in final edited form as:

Clin Geriatr Med. 2020 February ; 36(1): 53-67. doi:10.1016/j.cger.2019.09.002.

\title{
Orthostatic Hypotension in Parkinson Disease
}

\author{
Jose-Alberto Palma, MD, PhD [Associate Professor], \\ Department of Neurology, Dysautonomia Center, New York University School of Medicine, NY, \\ NYU Langone Health, 530 First Ave, Suite 9Q, New York, NY 10016 \\ Horacio Kaufmann, MD [Professor] \\ Department of Neurology, Dysautonomia Center, New York University School of Medicine, NY, \\ NYU Langone Health, 530 First Ave, Suite 9Q, New York, NY 10016
}

\section{Keywords}

Autonomic failure; Baroreflex dysfunction; Droxidopa; Midodrine; Norepinephrine; Neurogenic orthostatic hypotension

\section{INTRODUCTION}

Dysfunction of the autonomic nervous system is a characteristic feature of patients with Parkinson disease (PD) and other synucleinopathies, a group of neurodegenerative diseases caused by the abnormal accumulation of misfolded phosphorylated a-synuclein (aSyn) in neurons, glia or both.

Converging evidence indicates that abnormal aSyn spreads from cell to cell in a prion-like fashion ${ }^{1-3}$ and that different types of aSyn assemblies with different structural characteristics called strains ${ }^{4,5}$ may account for the different clinical phenotypes as they determine the nerve cell type and the regions of the nervous system that are affected. ${ }^{4}$ In patients with Parkinson disease (PD), dementia with Lewy bodies (DLB) and pure autonomic failure (PAF) aggregates of misfolded aSyn accumulate in the neuronal soma and throughout axons, called Lewy bodies (LB) and Lewy neurites, and peripheral autonomic neurons are always affected. In these patients, neurodegeneration usually progresses slowly with only a minor impact on survival. ${ }^{6}$ In patients with multiple system atrophy (MSA), a rare and devastating disease, aSyn accumulates primarily in oligodendroglia although

Corresponding author: Dr. Kaufmann. Horacio.Kaufmann@nyulangone.org.

Disclosures:

Dr. Palma has served on advisory boards of Lunbeck and Biogen. Dr. Palma is the principal investigator in clinical trials for neurogenic orthostatic hypotension sponsored by Theravance. Dr. Palma is Managing Editor of Clinical Autonomic Research. Dr. Palma has received grant support from the NIH, FDA, Familial Dysautonomia Foundation, and Michael J. Fox Foundation. Dr. Kaufmann has served on advisory boards of Lunbeck, Biogen, Biohaven and Theravance. He has been principal investigator in clinical trials for neurogenic orthostatic hypotension sponsored by Chelsea and Theravance. Dr. Kaufmann is Editor-in-Chief of Clinical Autonomic Research. Dr. Kaufmann has received grant support from the NIH, FDA, Familial Dysautonomia Foundation, and Michael J. Fox Foundation.

Publisher's Disclaimer: This is a PDF file of an unedited manuscript that has been accepted for publication. As a service to our customers we are providing this early version of the manuscript. The manuscript will undergo copyediting, typesetting, and review of the resulting proof before it is published in its final form. Please note that during the production process errors may be discovered which could affect the content, and all legal disclaimers that apply to the journal pertain. 
neurons are also affected. ${ }^{7,8}$ Autonomic dysfunction in synucleinopathies occurs at all stages of the disease and occasionally is its only manifestation. ${ }^{9}$

Among the most debilitating manifestations of autonomic dysfunction in PD is orthostatic hypotension $(\mathrm{OH})$, which is a sustained fall in blood pressure (BP) on standing. The current definition of $\mathrm{OH}$, based on expert consensus, ${ }^{10}$ is a fall of at least $20 \mathrm{mmHg}$ in systolic BP or $10 \mathrm{mmHg}$ in diastolic BP within 3 minutes of standing or upright tilt. $\mathrm{OH}$ can impair perfusion to organs above the heart, most notably the brain, resulting in symptoms of tissue hypoperfusion. Symptoms can be very disabling, have a profound impact on a patient's quality of life, and increase morbidity and mortality. ${ }^{11,12}$

In $\mathrm{PD}$ and other synucleinopathies, $\mathrm{OH}$ is neurogenic $(\mathrm{nOH})$, i.e., due to reduced norepinephrine release from postganglionic efferent sympathetic nerves, resulting in defective vasoconstriction when assuming the upright posture (Figure 1). ${ }^{10}$ Complicating nOH management is arterial hypertension when supine ( $\mathrm{SH}$ ), which occurs in up to $50 \%$ of patients with efferent baroreflex failure. ${ }^{13,14}$ When recognized, $\mathrm{nOH}$ can be treated, sometimes successfully. Discontinuation of potentially causative/aggravating drugs, patient education, non-pharmacological approaches, and pathophysiology-based drug therapy are key to an effective management.

Here we review the epidemiology, evaluation, and management of $\mathrm{nOH}$, with emphasis on patients with PD, summarize the non-pharmacologic and pharmacologic treatment strategies, and provide practical advice on the management of patients with this debilitating condition.

\section{EPIDEMIOLOGY}

In cross-sectional studies, between $30-50 \%$ of patients with PD have OH. ${ }^{14-17}$ The prevalence of $\mathrm{OH}$ in $\mathrm{PD}$ increases with age and disease duration. ${ }^{14}$ Although the prevalence of nOH in PD is relatively high, not all patients have symptoms of organ hypoperfusion and only a third of patients ( 16\%) had symptomatic nOH. ${ }^{14}$ Symptomatic nOH in PD is typically associated with an upright mean BP below $75 \mathrm{mmHg}$. This value (a standing mean BP $<75 \mathrm{mmHg}$ ) has a sensitivity of $97 \%$ and a specificity of $98 \%$ for detecting symptomatic $\mathrm{nOH}$, and appears to be the lower limit of cerebrovascular autoregulation in patients with PD and $\mathrm{nOH}$, below which patients develop symptoms of cerebral hypoperfusion. Patients fulfilling criteria for $\mathrm{nOH}$ that also had $\mathrm{SH}$ are less likely to develop symptomatic $\mathrm{nOH}$ after 3-min standing.

\section{PATHOPHYSIOLOGY}

Normally, unloading of the baroreceptors by standing up triggers norepinephrine release from postganglionic sympathetic efferent nerves causing vasoconstriction, which maintains $\mathrm{BP}$ in the standing position. This compensatory vasoconstriction is absent or attenuated in patients with synucleinopathies resulting in $\mathrm{nOH}$. In patients with $\mathrm{PD}$, baroreflex dysfunction is predominantly due to degeneration of post-ganglionic efferent sympathetic neurons. There is robust imaging and neuropathological data showing that post-ganglionic efferent sympathetic neurons innervating the myocardium are functionally affected due to 
aSyn deposits and fiber loss. ${ }^{18,}{ }^{19}$ Sympathetic fibers innervating blood vessels are also affected. This results in impaired norepinephrine release and defective vasoconstriction upon standing causing the BP to fall (i.e., nOH). ${ }^{16,}{ }^{19}$ Plasma norepinephrine, a marker of sympathetic neuronal integrity, is lower in patients with $\mathrm{PD}$ and $\mathrm{nOH}$ than in those without nOH. ${ }^{20}$

\section{APPROACH TO THE PATIENT WITH ORTHOSTATIC HYPOTENSION}

$\mathrm{OH}$ can be symptomatic or asymptomatic. Typical symptoms of $\mathrm{OH}$ are lightheadedness, dizziness, blurry vision, and, when the fall in BP is pronounced, loss of consciousness and postural tone (syncope). Symptoms occur only when standing, less frequently when sitting, and abate when lying down. Patients with $\mathrm{OH}$ may also complain of generalized weakness, fatigue, leg buckling, occipital headache, neck and shoulder ("coat hanger") discomfort, and shortness of breath due to ventilation/perfusion mismatch in the apical lung areas.

Patients with chronic $\mathrm{nOH}$ due to neurological disorders usually tolerate very low BPs with only mild or no symptoms at all but syncope can occur with added orthostatic stressors (e.g., large carbohydrate-rich meals, alcohol intake, very warm weather, dehydration, and antihypertensive treatment).

Symptoms of $\mathrm{OH}$ typically disappear after the patient resumes the sitting or lying position because cerebral blood flow is restored to levels above the lower limit of autoregulatory capacity (Figure 1). The chronic nature of $\mathrm{nOH}$ allows remarkable adaptive changes in cerebral autoregulatory mechanisms. ${ }^{21}$ Indeed, patients with $\mathrm{nOH}$ are frequently able to tolerate wide swings in BPs and often remain conscious at pressures that would otherwise induce syncope in healthy subjects. ${ }^{22}$

Symptoms of nOH can be non-specific, including fatigue and difficultly concentrating and may sometimes mimic a levodopa "off' motor state in PD patients. In these cases, the diagnosis of nOH may be missed unless $\mathrm{BP}$ is measured in the standing position. Conversely, it is important to realize that in patients with PD postural lightheadedness mimicking nOH may be caused by abnormal postural reflexes, vestibular deficits or orthostatic tremor. $^{23}$

In contrast to vasovagal (neurally-mediated) syncope, syncope in nOH occurs without signs of autonomic activation such as diaphoresis, tachycardia, nausea or abdominal discomfort. Following syncope, as soon as they resume the supine position, patients with nOH usually recover quickly and may be unaware of the event. Patients report that symptom severity varies from day-to-day and fluctuates throughout the day. The morning hours tend to be most difficult as $\mathrm{OH}$ symptoms are aggravated by intravascular volume loss overnight. ${ }^{24}$ Meals, particularly carbohydrate-rich, lead to splanchnic vasodilatation and post-prandial hypotension (i.e., fall in BP within 2 hours of eating). The severity of postprandial hypotension is directly related to insulin release. ${ }^{25}$ This has therapeutic implications as will be later discussed. Physical inactivity and prolonged bed rest are common in patients with $\mathrm{nOH}$. This leads to cardiovascular deconditioning further worsening the fall in $\mathrm{BP}$ and increasing symptoms leading to a vicious cycle. 
Patients at high risk should be routinely screened for $\mathrm{OH}$, even in the absence of symptoms. These include patients with a synucleinopathy (PD/DLB, MSA or PAF), elderly subjects (>70 years old), or on multiple medications.

\section{DIAGNOSIS OF NEUROGENIC ORTHOSTATIC HYPOTENSION}

In patients presenting with "orthostatic intolerance" (i.e., difficulty maintaining the upright position) it is necessary to determine whether symptoms are due to orthostatic hypotension or to other causes (Table 1).

The diagnosis of $\mathrm{OH}$ requires $\mathrm{BP}$ readings while supine and upright, either during active standing or during a tilt-table test, to determine the presence of a sustained orthostatic fall of at least $20 \mathrm{mmHg}$ systolic or $10 \mathrm{mmHg}$ diastolic BP. BP and heart rate should be measured after the patient has been supine for several minutes and after standing still (or passively tilted) for 1-3 minutes. The magnitude of the BP fall and symptom severity vary at different times of the day; thus it may be necessary to re-test the patient in the morning when the orthostatic fall in pressure is more pronounced or after a meal if the history suggest postprandial hypotension.

In patients reporting typical symptoms but without a fall in blood pressure within 3 minutes of standing, a more prolonged orthostatic stress with a tilt-table test may be necessary to define the condition. Patients with milder or earlier forms of efferent baroreflex failure may experience orthostatic hypotension after longer time standing (i.e., delayed orthostatic hypotension). ${ }^{26,27}$ Patients with symptoms mimicking those of orthostatic hypotension but without an identified fall in blood pressure are not infrequent and include those with vestibular disorders, gait abnormalities, alcohol and drugs that depress the CNS, and the inebriation-like syndrome. ${ }^{23}$ Conversely, patients with cognitive impairment may not accurately identify symptoms of organ hypoperfusion, despite low blood pressure when standing. ${ }^{28}$

If sustained orthostatic hypotension is confirmed, it is key to establish whether the cause is a pathological lesion in sympathetic neurons (i.e., neurogenic orthostatic hypotension) or if it is secondary to other medical causes (i.e., non-neurogenic orthostatic hypotension) such as anemia- or dehydration-related volume depletion, excessive venous pooling sometimes aggravated by varicose veins, or medication side effects (e.g., anti-hypertensive agents, diuretics, tricyclic antidepressants, opioids, benzodiazepines, antiparkinsonian agents, etc.). Several features are useful to distinguish neurogenic vs. non-neurogenic orthostatic hypotension (Table 1). A heart rate increase of at least 0.5 beat per minute for each $\mathrm{mmHg}$ fall in systolic blood pressure (i.e., $\Delta \mathrm{HR} / \Delta \mathrm{SBP}$ ratio $\geq 0.5 \mathrm{bpm} / \mathrm{mmHg}$ ) has very high sensitivity and specificity to diagnose non-neurogenic orthostatic hypotension. Conversely, a $\Delta \mathrm{HR} / \Delta \mathrm{SBP}$ ratio $<0.5 \mathrm{bpm} / \mathrm{mmHg}$ indicates neurogenic orthostatic hypotension. ${ }^{29}$

Ambulatory BP monitoring (ABPM) can assist in the diagnosis and management of $\mathrm{nOH}^{30}$. Affected patients typically have a reversal of the normal circadian blood pressure pattern with higher BP during the night when the patient is supine in bed than during the day. Nocturnal SH causes pressure natriuresis with exaggerated sodium and water loss causing 
overnight depletion of intravascular volume, worsening $\mathrm{OH}$ in the morning. $\mathrm{ABPM}$ and a detailed diary of activities is also useful to specifically tailor the use of short acting pressor agents only at times when $\mathrm{OH}$ is severe in patients that may remain seated for long periods of the day or are wheelchair-bound.

\section{MANAGEMENT OF NEUROGENIC ORTHOSTATIC HYPOTENSION}

The goal of treatment is not to normalize standing BP, but to reduce symptom burden, to improve quality of life. Consensus guidelines for the treatment of nOH are currently lacking and there are no long-term studies analyzing the impact of treatment on survival, falls, or quality of life.

A noteworthy percentage of patients with $\mathrm{nOH}$ also have $\mathrm{SH}$, which poses a difficult therapeutic challenge. In a multicenter study including 210 patients with PD from the US and Europe, $44 \%$ had a supine BP $>140 / 90 \mathrm{mmHg} .{ }^{14}$ Similar results (45\% prevalence of $\mathrm{SH})$ were found in a sample of 72 patients with PD from Japan. ${ }^{31}$ Another study found that $71 \%$ of patients with PD had absent or reversed nocturnal BP dipping, as measured by ABPM, which is another way of quantifying $\mathrm{SH} .{ }^{13}$

Drugs that can increase BP while in the upright position can worsen SH. Therefore, pharmacological treatment of $\mathrm{nOH}$ requires careful consideration of the potential risks and actual benefits.

The steps in management include: a) correcting aggravating factors, b) implementing nonpharmacological measures and c) drug therapies.

\section{Correction of aggravating factors}

Drugs that reduce intravascular volume (diuretics), induce vasodilatation (sildenafil, nitrates), or block norepinephrine release/activity at the neurovascular junction (a-blockers, centrally acting $\mathrm{a}_{2}$-agonists, tricyclic antidepressants) worsen $\mathrm{nOH}$ and symptoms. Levodopa and dopamine agonists may also lower BP and a dose adjustment may be considered based on an individual risk-benefit assessment. ${ }^{32-35}$ Anemia should be investigated and treated. ${ }^{36}$ Erythropoietin (25-50 units $/ \mathrm{kg}$, subcutaneous, 3 times a week) in conjunction with iron supplements may be beneficial in patients with nOH and anemia. ${ }^{37}$

\section{Non-pharmacologic treatment and patient education}

Non-pharmacologic measures are summarized in Box 1. Patients should be aware of the diuretic effects of caffeine and alcohol and avoid sugary beverages (e.g., bottled juices, sodas) due to the hypotensive effects of high-glycemic index carbohydrates. ${ }^{25}$ Fluid intake should be 2-2.5 L per day. Patients should be encouraged to increase salt intake by adding $1-2$ teaspoon of salt to a healthy diet. Other patients prefer using $0.5-1.0 \mathrm{~g}$ salt tablets although they can cause abdominal discomfort. In patients with $\mathrm{nOH}$, drinking $0.5 \mathrm{~L}$ of water produces a marked increase in $\mathrm{BP}^{38}$ This can be used as a rescue measure since the pressor effect is quick (peaks in around 30-min) although short-lived. 
Symptomatic nOH can quickly lead to a reluctance to stand up and avoidance of physical activity. In turn, physical immobility worsens $\mathrm{OH}$, leading to a "vicious cycle" of deconditioning. ${ }^{11}$ Physical exercise is therefore a key component of the therapeutic regimen but because physical activity in the standing position can worsen hypotension in patients with efferent baroreflex failure, ${ }^{39-42}$ exercise should be performed in the recumbent or sitting position using a recumbent stationary bicycle or rowing machine. The exception is exercise in a pool as the hydrostatic pressure of water allows upright exercise without hypotension. ${ }^{43}$ Patients should be taught specific physical countermaneuvers. ${ }^{44}$ Eating results in blood pooling within the splanchnic circulation and patients can become severely hypotensive within 2 -h of eating (i.e., postprandial hypotension), particularly after carbohydrate-rich meals. ${ }^{10,45-47}$ Eating smaller, more frequent meals, and reducing carbohydrates can improve postprandial hypotension. Alcohol is also a vasodilator and should be reserved for the evening, prior to going to bed.

Patients should be instructed to change positions gradually, and briefly sit before standing. Straining and Valsalva-like maneuvers during bowel movements are a common cause of syncope. ${ }^{48}$ If this is the case, constipation must be treated aggressively. ${ }^{49}$ High-waist compression stockings producing at least $15-20 \mathrm{mmHg}$ of pressure can increase BP by augmenting venous return. ${ }^{50}$ Patients with movement disorders struggle to put the stockings on, which limits their usefulness in everyday life. Elastic abdominal binders are a good alternative. ${ }^{51,52}$ A recently developed abdominal binder that inflates automatically only on standing had promising results in patients with $\mathrm{nOH} .{ }^{53}$

\section{PHARMACOLOGIC MANAGEMENT}

While non-pharmacologic methods are very effective when performed properly, many patients with nOH still require pharmacologic treatment to improve symptoms. Two complementary strategies are used: a) Expanding intravascular volume with the synthetic mineralocorticoid fludrocortisone and b) Increasing peripheral vascular resistance with the pressor agents midodrine or droxidopa. Selection of one or the others or both depends on the specific features and needs of each patient. Fludrocortisone can be combined with midodrine or droxidopa. No studies have directly compared midodrine and droxidopa, so whether one exerts more symptomatic relief than the other is unknown.

All available drugs that raise $\mathrm{BP}$ in the standing position also raise $\mathrm{BP}$ in the supine position, therefore increasing the risk or worsening SH. Although there are no specific data on cardioand cerebrovascular events induced by $\mathrm{SH}$ in patients with $\mathrm{nOH}$, treating physicians should be aware of this potential side effect. Before beginning treatment with fludrocortisone, midodrine or droxidopa, the patient's medication should be carefully reviewed.

Combination therapy of agents that increase BP (e.g., fludrocortisone, ephedrine, midodrine, droxidopa and triptans) increases the risk of $\mathrm{SH}$.

Patients should be instructed to avoid the supine position during the day, to sleep with the head of the bed raised 30-degrees, and to ensure that they take their final dose of droxidopa or midodrine at least 4-h before bedtime. Droxidopa or midodrine should be reduced and, if 
necessary, discontinued if severe SH persists. BP should be rechecked supine at a 30-degree angle if increased doses are required. Safety in patients with BP higher than $180 \mathrm{mmHg}$ at a 30-degree angle has not been established as these patients were excluded from the clinical trials that led to drug approval.

\section{Fludrocortisone:}

Fludrocortisone (9a-fluorocortisol) is a synthetic mineralocorticoid that increases renal sodium and water re-absorption, therefore expanding intravascular volume and increasing blood pressure in all positions. Experimental data suggest that fludrocortisone enhance the pressor effect of norepinephrine and angiotensin II. Although not specifically approved by the U.S. Food and Drug Administration for this indication, fludrocortisone is perhaps the most frequently prescribed agent for the treatment of orthostatic hypotension. Because activation of renal mineralocorticoid receptors results in inflammation and fibrosis and may have a direct nephrotoxic effect leading to a faster decline in renal function and hypertension, ${ }^{54}$ fludrocortisone should be used with extreme caution in the treatment of orthostatic hypotension, preferably for short-term periods, and dosage should never be higher than $0.2 \mathrm{mg} /$ day. Higher dosages do not have improved therapeutic effects but do intensify side effects. Fludrocortisone usually requires at least 7-10 days of treatment to exert any significant clinical effect. Short-term side effects are frequent and include supine hypertension, hypokalemia and ankle edema. ${ }^{55}$ To reduce the risk of hypokalemia, patients taking fludrocortisone should be instructed to eat potassium-rich foods or to take potassium supplements (potassium chloride $20 \mathrm{mEq}$ a day). Long-term use exacerbates permanent hypertension and target damage ${ }^{54}$, including left ventricular hypertrophy ${ }^{56}$ and renal failure $^{54}$ and is associated with a higher risk of all-cause hospitalization in patients with orthostatic hypotension. ${ }^{57}$

\section{Midodrine:}

Midodrine is an oral $a_{1}$-adrenoceptor agonist that induces vasoconstriction and increases BP. ${ }^{58-61}$ Midodrine is approved for the treatment of symptomatic OH in the U.S., Europe and Asia. Midodrine raises BP in the standing, sitting, and supine positions and its pressor effect is noticeable $\sim 30-45$ minutes after consumption, reaching a maximum after $\sim 1$ hour, and persists for a total of 2-3 hours. Treatment should begin with a 2.5 or $5 \mathrm{mg}$ dose, which can then be increased up to $10 \mathrm{mg}$ to be taken up to 3 times a day. $\mathrm{nSH}$ is common, hence patients should not take midodrine less than 3-4 hours before bedtime. Other adverse events owing to activation of a 1-adrenergic receptors are piloerection ("goosebumps"), itching of the scalp, and urinary retention. Midodrine has no effect on heart rate as it does not activate $\beta$-adrenoreceptors and, given its poor diffusion across the blood-brain barrier, has no CNS adverse effects. ${ }^{62}$

\section{Droxidopa:}

Droxidopa (L-threo-3,4-dihydroxyphenyl-serine, L-DOPS) is an oral synthetic amino acid that is converted to norepinephrine in the body. ${ }^{63}$ Droxidopa is decarboxylated to norepinephrine by the enzyme aromatic amino-acid decarboxylase (AAAD) the same enzyme the converts L-dopa to dopamine. Droxidopa was approved in Japan in 1989 for the treatment of nOH in PD, MSA, and familial amyloid polyneuropathy. In the U.S., the Food 
and Drug Administration (FDA) approved droxidopa in 2014 for the treatment of symptomatic nOH associated with PAF, PD, and MSA. ${ }^{64-68}$ Droxidopa is not approved in Europe. Extensive clinical experience shows that droxidopa is safe and well tolerated. ${ }^{69-77}$ Peak plasma concentrations of droxidopa are reached $\sim 3$-h after oral administration. The dosage used in clinical trials was 100-600 mg three times/day although clinical experience indicates that the dosage should be tailored to each patient's needs considering the periods of time when he/she is going to be active or inactive. ${ }^{63,70,75}$ Because the pressor effect of droxidopa varies among patients, a titration procedure supervised by a clinician is highly recommended. ${ }^{16}$ Ambulatory 24-hour BP monitoring (ABPM) is useful to evaluate the BP profile before and after initiating treatment with droxidopa. ${ }^{78}$

Inhibition of the AAAD with high doses of carbidopa can abolish the pressor effect of droxidopa by preventing its peripheral conversion to norepinephrine. This was shown in studies using a single $200 \mathrm{mg}$ dose of carbidopa administered 30-min before droxidopa. ${ }^{79} \mathrm{In}$ clinical practice the dose of carbidopa in patients treated with L-dopa is lower than $200 \mathrm{mg}$, thus carbidopa appears not to block the pressor effect of droxidopa significantly. ${ }^{69}$ Further studies are warranted to determine whether droxidopa has beneficial effects on other motor and non-motor symptoms that result from norepinephrine deficiency in patients with PD. ${ }^{80}$

\section{Norepinephrine reuptake inhibitors:}

An emerging approach in the treatment of neurogenic orthostatic hypotension is the use of inhibitors of the norepinephrine membrane transporter, which inhibit norepinephrine reuptake and increase its availability in the neurovascular junction.

In healthy subjects, norepinephrine reuptake inhibition has little effect on blood pressure. This is because, although norepinephrine reuptake inhibitors enhance noradrenergic vasoconstriction at the level of the sympathetic postganglionic fibers, this is counteracted norepinephrine-mediated central $\mathrm{a}_{2}$-receptors stimulation in the CNS, which has a vasodilator effect. However, in patients with central autonomic dysfunction, norepinephrine reuptake inhibitors result in only peripheral vasoconstriction, making this therapeutic group particularly suitable for patients with multiple system atrophy.

Short-term controlled clinical trials have shown that atomoxetine (10-18 $\mathrm{mg}$, twice a day) a short-acting norepinephrine reuptake inhibitor, increases standing blood pressure and reduces the burden of symptoms compared to placebo in patients with neurogenic orthostatic hypotension. ${ }^{81-83}$ The higher the norepinephrine levels, the greater the pressor effect and symptomatic improvement with atomoxetine, which makes it a particularly attractive option for patients with neurogenic orthostatic hypotension caused by autonomic decentralization (e.g., multiple system atrophy). ${ }^{84} \mathrm{~A}$ multicenter controlled trial to confirm the efficacy of atomoxetine in patients with neurogenic orthostatic hypotension is underway (ClinicalTrials.gov NCT02784535). A phase-2 trial with ampreloxetine (TD-9855), a longacting investigational norepinephrine reuptake inhibitor, showed that this compound was safe and increased blood pressure and orthostatic tolerance in patients with neurogenic orthostatic hypotension; a large multicenter phase-3 study to confirm this is ongoing (ClinicalTrials.gov NCT03750552). 
Conversely, lower supine plasma norepinephrine levels appear to predict a greater symptomatic and pressor response to droxidopa, a synthetic oral norepinephrine precursor. ${ }^{85}$ These responses can be explained by denervation supersensitivity of adrenergic receptors. ${ }^{86}$ Consequently, patients with low plasma norepinephrine levels (usually Lewy body disorders or peripheral autonomic neuropathies) may respond better to droxidopa and midodrine, ${ }^{85}$ whereas patients with normal or high norepinephrine levels (usually multiple system atrophy) may respond better to norepinephrine reuptake inhibitors.

In patients with refractory neurogenic orthostatic hypotension, norepinephrine reuptake inhibition could be theoretically combined with droxidopa or midodrine, with or without fludrocortisone or pyridostigmine. However, no safety data is available on the combined use of most of these agents, and extreme caution is advised.

Other medications-Pyridostigmine, an inhibitor of cholinesterase, the enzyme that catalyzes the hydrolysis of acetylcholine and terminates its action, potentiates cholinergic neurotransmission in autonomic ganglia, both sympathetic and parasympathetic. A double blind study showed that pyridostimine increases, on average, only $4 \mathrm{mmHg}$ in systolic blood pressure. ${ }^{87}$ The combination of $5 \mathrm{mg}$ midodrine with $60 \mathrm{mg}$ pyridostigmine was slightly more effective than pyridostigmine alone. Similarly, the combination of pyridostigmine with atomoxetine appears to have a synergistic effect to increase blood pressure and improve orthostatic tolerance. $^{88}$

Other agents such as the vasopressin analogue desmopressin (DDAVP), the centrally acting a2-antagonist yohimbine, the ergot alkaloid dihydroergotamine, and the non-selective adrenergic agonist pseudoephedrine are superseded and rarely used nowadays owing to their problematic adverse event profile.

\section{NEUROGENIC SUPINE HYPERTENSION}

The prevalence of neurogenic supine hypertension is 30-50\% in Parkinson diseases, $40 \%$ in multiple system atrophy and $50-70 \%$ in pure autonomic failure. ${ }^{89}$ Treatment of supine hypertension focuses on reducing blood pressure to lower the risk of target organ damage without worsening hypotension. Achieving this goal is challenging. Patients should avoid the supine position. For day naps patients should sit in a reclining chair with the feet on the floor. At night, tilting the head of the bed to a 30 or a 45-degree angle lowers blood pressure. 90 This is best accomplished with an electric bed or mattress. A carbohydrate-rich snack or an alcoholic drink before bedtime lowers blood pressure. The application of local abdominal heating pad to lower blood pressure by inducing splanchnic vasodilation is being currently studied in a clinical trial (ClinicalTrials.gov: NCT02417415).

In patients with severe prolonged supine hypertension at night in spite of elevation of the head of the bed (systolic blood pressure of at least $180 \mathrm{mmHg}$ or diastolic blood pressure of at least $110 \mathrm{mmHg}$ ), short-acting antihypertensives (e.g., captopril $25 \mathrm{mg}$, losartan $50 \mathrm{mg}$, or nitroglycerin patch $0.1 \mathrm{mg} / \mathrm{h}$ ) at bedtime could be considered, particularly in patients who already have organ damage, although none of these approaches has been studied in large controlled trials. ${ }^{24,91,92}$ Patients should be advised about the augmented risk of hypotension 
and falls if they stand up at nighttime, e.g., to urinate. To avoid this, the use of a urinal or bedside commode should be encouraged.

\section{CONCLUSIONS}

$\mathrm{nOH}$ is a disabling disorder that occurs frequently in patients with PD and other synucleinopathies. Mildly-moderately affected patients need a combination of nonpharmacological and pharmacological therapies, e.g., the synthetic mineralocorticoid fludrocortisone and the pressor agents midodrine or droxidopa. Severely affected patients are unable to stand but for a few seconds, making it impossible to perform even simple activities of daily living. The risk of falls and injuries is increased and patients can become socially isolated due to the burden of symptoms. In these severe cases of nOH success with available agents is only partial, and many patients continue to suffer severe symptoms. Exercise becomes intolerable, which inevitably leads to physical deconditioning and muscle atrophy, which, in turn, worsen the fall in BP. Despite its importance, there is a paucity of treatment options for this condition, the most recently available being droxidopa. New treatment options are needed.

\section{REFERENCES}

1. Woerman AL, Stohr J, Aoyagi A, et al. Propagation of prions causing synucleinopathies in cultured cells. Proc Natl Acad Sci USA 2015; 11:E4949-58.

2. Masuda-Suzukake M, Nonaka T, Hosokawa M, et al. Prion-like spreading of pathological alphasynuclein in brain. Brain 2013;136:1128-38. [PubMed: 23466394]

3. Prusiner SB, Woerman AL, Mordes DA, et al. Evidence for alpha-synuclein prions causing multiple system atrophy in humans with parkinsonism. Proc Natl Acad Sci USA 2015; 112:E5308-5317. [PubMed: 26324905]

4. Peelaerts W, Bousset L, Van der Perren A, et al. alpha-Synuclein strains cause distinct synucleinopathies after local and systemic administration. Nature 2015;522:340-4. [PubMed: 26061766]

5. Peelaerts W, Baekelandt V. a-Synuclein strains and the variable pathologies of synucleinopathies. J Neurochem 2016; 139 Suppl 1:256-74.

6. Marras C, McDermott MP, Rochon PA, et al. Survival in Parkinson disease: thirteen-year follow-up of the DATATOP cohort. Neurology 2005;64:87-93. [PubMed: 15642909]

7. Halliday GM. Re-evaluating the glio-centric view of multiple system atrophy by highlighting the neuronal involvement. Brain 2015;138:2116-9. [PubMed: 26205836]

8. Cykowski MD, Coon EA, Powell SZ, et al. Expanding the spectrum of neuronal pathology in multiple system atrophy. Brain 2015;138:2293-309. [PubMed: 25981961]

9. Kaufmann H, Norcliffe-Kaufmann L, Palma JA, et al. Natural history of pure autonomic failure: A United States prospective cohort. Ann Neurol 2017;81:287-97. [PubMed: 28093795]

10. Freeman R, Wieling W, Axelrod FB, et al. Consensus statement on the definition of orthostatic hypotension, neurally mediated syncope and the postural tachycardia syndrome. Clin Auton Res 2011;21:69-72. [PubMed: 21431947]

11. Freeman R Clinical practice. Neurogenic orthostatic hypotension. N Engl J Med 2008;358:615-24. [PubMed: 18256396]

12. Masaki KH, Schatz IJ, Burchfiel CM, et al. Orthostatic hypotension predicts mortality in elderly men: the Honolulu Heart Program. Circulation 1998;98:2290-5. [PubMed: 9826316]

13. Berganzo K, Diez-Arrola B, Tijero B, et al. Nocturnal hypertension and dysautonomia in patients with Parkinson's disease: are they related? J Neurol 2013;260:1752-6. [PubMed: 23412356] 
14. Palma JA, Gomez-Esteban JC, Norcliffe-Kaufmann L, et al. Orthostatic hypotension in Parkinson disease: how much you fall or how low you go? Mov Disord 2015;30:639-45. [PubMed: 25678194]

15. Velseboer DC, de Haan RJ, Wieling W, Goldstein DS, de Bie RM. Prevalence of orthostatic hypotension in Parkinson's disease: a systematic review and meta-analysis. Parkinsonism Rel Disord 2011;17:724-9.

16. Palma JA, Kaufmann H. Epidemiology, Diagnosis, and Management of Neurogenic Orthostatic Hypotension. Mov Disord Clin Pract 2017;4:298-308. [PubMed: 28713844]

17. Thaisetthawatkul P, Boeve BF, Benarroch EE, et al. Autonomic dysfunction in dementia with Lewy bodies. Neurology 2004;62:1804-9. [PubMed: 15159482]

18. Kaufmann H, Goldstein DS. Autonomic dysfunction in Parkinson disease. Handb Clin Neurol 2013;117:259-278. [PubMed: 24095131]

19. Jain S, Goldstein DS. Cardiovascular dysautonomia in Parkinson disease: from pathophysiology to pathogenesis. Neurobio Dis 2012;46:572-80.

20. Goldstein DS, Holmes CS, Dendi R, Bruce SR, Li ST. Orthostatic hypotension from sympathetic denervation in Parkinson's disease. Neurology 2002;58:1247-1255. [PubMed: 11971094]

21. Fuente Mora C, Palma JA, Kaufmann H, Norcliffe-Kaufmann L. Cerebral autoregulation and symptoms of orthostatic hypotension in familial dysautonomia. J Cereb Blood Flow Metab 2016.

22. Horowitz DR, Kaufmann H. Autoregulatory cerebral vasodilation occurs during orthostatic hypotension in patients with primary autonomic failure. Clin Auton Res 2001;11:363-367. [PubMed: 11794717]

23. Palma JA, Norcliffe-Kaufmann L, Kaufmann H. An orthostatic hypotension mimic: The inebriation-like syndrome in Parkinson disease. Mov Disord 2016;31:598-600. [PubMed: 26879239]

24. Arnold AC, Biaggioni I. Management approaches to hypertension in autonomic failure. Curr Opin Nephrol Hypertens 2012;21:481-5. [PubMed: 22801444]

25. Shibao C, Gamboa A, Diedrich A, et al. Acarbose, an alpha-glucosidase inhibitor, attenuates postprandial hypotension in autonomic failure. Hypertension 2007;50:54-61. [PubMed: 17515447]

26. Gibbons CH, Freeman R. Clinical implications of delayed orthostatic hypotension: A 10-year follow-up study. Neurology 2015;85:1362-67. [PubMed: 26400576]

27. Cheshire WP Jr.. Clinical classification of orthostatic hypotensions. Clin Auton Res 2017;27:133135. [PubMed: 28349278]

28. Bengtsson-Lindberg M, Larsson V, Minthon L, Wattmo C, Londos E. Lack of orthostatic symptoms in dementia patients with orthostatic hypotension. Clin Auton Res 2015;25:87-94. [PubMed: 24743866]

29. Norcliffe-Kaufmann L, Kaufmann H, Palma JA, et al. Orthostatic heart rate changes in patients with autonomic failure caused by neurodegenerative synucleinopathies. Ann Neurol 2018;83:522531. [PubMed: 29405350]

30. Norcliffe-Kaufmann L, Kaufmann H. Is ambulatory blood pressure monitoring useful in patients with chronic autonomic failure? Clin Auton Res 2014;24:189-92. [PubMed: 24710680]

31. Umehara T, Matsuno H, Toyoda C, Oka H. Clinical characteristics of supine hypertension in de novo Parkinson disease. Clin Auton Res 2016;26:15-21. [PubMed: 26613721]

32. Rose KM, Eigenbrodt ML, Biga RL, et al. Orthostatic hypotension predicts mortality in middleaged adults: the Atherosclerosis Risk In Communities (ARIC) Study. Circulation 2006;114:630-6. [PubMed: 16894039]

33. Rose KM, Tyroler HA, Nardo CJ, et al. Orthostatic hypotension and the incidence of coronary heart disease: the Atherosclerosis Risk in Communities study. Am J Hypertens 2000;13:571-8. [PubMed: 10912737]

34. Kamaruzzaman S, Watt H, Carson C, Ebrahim S. The association between orthostatic hypotension and medication use in the British Women's Heart and Health Study. Age Ageing 2010;39:51-6. [PubMed: 19897539]

35. Fotherby MD, Potter JF. Orthostatic hypotension and anti-hypertensive therapy in the elderly. Postgrad Med J 1994;70:878-81. [PubMed: 7870633] 
36. Biaggioni I, Robertson D, Krantz S, Jones M, Haile V. The anemia of primary autonomic failure and its reversal with recombinant erythropoietin. Ann Intern Med 1994; 121:181-6. [PubMed: 8017744]

37. Perera R, Isola L, Kaufmann H. Effect of recombinant erythropoietin on anemia and orthostatic hypotension in primary autonomic failure. Clin Auton Res 1995;5:211-213. [PubMed: 8520216]

38. May M, Jordan J. The osmopressor response to water drinking. Am J Physiol Regul Integr Comp Physiol 2011;300:R40-46. [PubMed: 21048076]

39. Low DA, Vichayanrat E, Iodice V, Mathias CJ. Exercise hemodynamics in Parkinson's disease and autonomic dysfunction. Parkinsonism Rel Disord 2014;20:549-53.

40. Puvi-Rajasingham S, Smith GD, Akinola A, Mathias CJ. Abnormal regional blood flow responses during and after exercise in human sympathetic denervation. J Physiol 1997;505 ( Pt 3):841-9. [PubMed: 9457657]

41. Smith GD, Mathias CJ. Postural hypotension enhanced by exercise in patients with chronic autonomic failure. QJM 1995;88:251-6. [PubMed: 7796074]

42. Smith GD, Watson LP, Mathias CJ. Neurohumoral, peptidergic and biochemical responses to supine exercise in two groups with primary autonomic failure: Shy-Drager syndrome/multiple system atrophy and pure autonomic failure. Clin Auton Res 1996;6:255-62. [PubMed: 8899251]

43. Rowell LB. Human Circulation: Regulation During Physical Stress. New York: Oxford University Press, 1986.

44. Wieling W, van Lieshout JJ, van Leeuwen AM. Physical manoeuvres that reduce postural hypotension in autonomic failure. Clin Auton Res 1993;3:57-65. [PubMed: 8477182]

45. Kooner JS, Raimbach S, Watson L, Bannister R, Peart S, Mathias CJ. Relationship between splanchnic vasodilation and postprandial hypotension in patients with primary autonomic failure. $\mathrm{J}$ Hypertens Suppl 1989;7:S40-41. [PubMed: 2632742]

46. Jansen RW, Lipsitz LA. Postprandial hypotension: epidemiology, pathophysiology, and clinical management. Ann Intern Med 1995;122:286-95. [PubMed: 7825766]

47. Pavelic A, Krbot Skoric M, Crnosija L, Habek M. Postprandial hypotension in neurological disorders: systematic review and meta-analysis. Clin Auton Res 2017;27:263-71. [PubMed: 28647892]

48. Goldstein DS, Cheshire WP Jr. Beat-to-beat blood pressure and heart rate responses to the Valsalva maneuver. Clin Auton Res 2017; 27(6):361-7. [PubMed: 29052077]

49. Krediet CT, van Lieshout JJ, Bogert LW, Immink RV, Kim YS, Wieling W. Leg crossing improves orthostatic tolerance in healthy subjects: a placebo-controlled crossover study. Am J Physiol Heart Circ Physiol 2006;291:H1768-72. [PubMed: 16714361]

50. Diedrich A, Biaggioni I. Segmental orthostatic fluid shifts. Clin Auton Res 2004; 14:146-147. [PubMed: 15241642]

51. Smit AA, Wieling W, Fujimura J, et al. Use of lower abdominal compression to combat orthostatic hypotension in patients with autonomic dysfunction. Clin Auton Res 2004;14:167-175. [PubMed: 15241645]

52. Fanciulli A, Goebel G, Metzler B, et al. Elastic Abdominal Binders Attenuate Orthostatic Hypotension in Parkinson's Disease. Mov Disord Clin Pract 2016;3:156-60. [PubMed: 30363559]

53. Okamoto LE, Diedrich A, Baudenbacher FJ, et al. Efficacy of Servo-Controlled Splanchnic Venous Compression in the Treatment of Orthostatic Hypotension: A Randomized Comparison With Midodrine. Hypertension 2016;68:418-26. [PubMed: 27271310]

54. Norcliffe-Kaufmann L, Axelrod FB, Kaufmann H. Developmental abnormalities, blood pressure variability and renal disease in Riley Day syndrome. J Hum Hypertens 2013;27:51-55. [PubMed: 22129610]

55. Chobanian AV, Volicer L, Tifft CP, Gavras H, Liang CS, Faxon D. Mineralocorticoid-induced hypertension in patients with orthostatic hypotension. N Engl J Med 1979;301:68-73. [PubMed: 449947]

56. Vagaonescu TD, Saadia D, Tuhrim S, Phillips RA, Kaufmann H. Hypertensive cardiovascular damage in patients with primary autonomic failure. Lancet 2000;355:725-6. [PubMed: 10703810] 
57. Grijalva CG, Biaggioni I, Griffin MR, Shibao CA. Fludrocortisone Is Associated With a Higher Risk of All-Cause Hospitalizations Compared With Midodrine in Patients With Orthostatic Hypotension. J Am Heart Assoc 2017;6.

58. Jankovic J, Gilden JL, Hiner BC, et al. Neurogenic orthostatic hypotension: a double-blind, placebo-controlled study with midodrine. Am J Med 1993;95:38-48. [PubMed: 7687093]

59. Low PA, Gilden JL, Freeman R, Sheng KN, McElligott MA. Efficacy of midodrine vs placebo in neurogenic orthostatic hypotension. A randomized, double-blind multicenter study. Midodrine Study Group. JAMA 1997;277:1046-51.

60. Wright RA, Kaufmann HC, Perera R, et al. A double-blind, dose-response study of midodrine in neurogenic orthostatic hypotension. Neurology 1998;51:120-4. [PubMed: 9674789]

61. Smith W, Wan H, Much D, Robinson AG, Martin P. Clinical benefit of midodrine hydrochloride in symptomatic orthostatic hypotension: a phase 4, double-blind, placebo-controlled, randomized, tilt-table study. Clin Auton Res 2016;26:269-277. [PubMed: 27372462]

62. McTavish D, Goa KL. Midodrine. A review of its pharmacological properties and therapeutic use in orthostatic hypotension and secondary hypotensive disorders. Drugs 1989;38:757-77. [PubMed: 2480881]

63. Kaufmann H, Norcliffe-Kaufmann L, Palma JA. Droxidopa in neurogenic orthostatic hypotension. Expert Rev Cardiovasc Ther 2015;13:875-91. [PubMed: 26092297]

64. Kaufmann H, Biaggioni I. Autonomic failure in neurodegenerative disorders. Semin Neurol 2003;23:351-63. [PubMed: 15088256]

65. Kaufmann H, Malamut R, Norcliffe-Kaufmann L, Rosa K, Freeman R. The Orthostatic Hypotension Questionnaire (OHQ): validation of a novel symptom assessment scale. Clin Auton Res 2012;22:79-90. [PubMed: 22045363]

66. Kaufmann H, Freeman R, Biaggioni I, et al. Droxidopa for neurogenic orthostatic hypotension: a randomized, placebo-controlled, phase 3 trial. Neurology 2014;83:328-35. [PubMed: 24944260]

67. Hauser RA, Isaacson S, Lisk JP, Hewitt LA, Rowse G. Droxidopa for the short-term treatment of symptomatic neurogenic orthostatic hypotension in Parkinson's disease (nOH306B). Mov Disord 2015;30:646-54. [PubMed: 25487613]

68. Elgebaly A, Abdelazeim B, Mattar O, Gadelkarim M, Salah R, Negida A. Meta-analysis of the safety and efficacy of droxidopa for neurogenic orthostatic hypotension. Clin Auton Res 2016;26:171-80. [PubMed: 26951135]

69. Kaufmann H Droxidopa for symptomatic neurogenic orthostatic hypotension: what can we learn? Clin Auton Res 2017;27:1-3.

70. Gupta F, Karabin B, Mehdirad A. Titrating droxidopa to maximize symptomatic benefit in a patient with Parkinson disease and neurogenic orthostatic hypotension. Clin Auton Res 2017;27:15-16. [PubMed: 28699047]

71. Vernino S, Claassen D. Polypharmacy: droxidopa to treat neurogenic orthostatic hypotension in a patient with Parkinson disease and type 2 diabetes mellitus. Clin Auton Res 2017;27:33-34. [PubMed: 28674868]

72. Kremens D, Lew M, Claassen D, Goodman BP. Adding droxidopa to fludrocortisone or midodrine in a patient with neurogenic orthostatic hypotension and Parkinson disease. Clin Auton Res 2017;27:29-31. [PubMed: 28674867]

73. Mehdirad A, Karabin B, Gupta F. Managing neurogenic orthostatic hypotension with droxidopa in a patient with Parkinson disease, atrial fibrillation, and hypertension. Clin Auton Res 2017;27:2527.

74. Claassen D, Lew M. Initiating droxidopa for neurogenic orthostatic hypotension in a patient with Parkinson disease. Clin Auton Res 2017;27:13-14. [PubMed: 28631224]

75. Goodman BP, Claassen D, Mehdirad A. Adjusting droxidopa for neurogenic orthostatic hypotension in a patient with Parkinson disease. Clin Auton Res 2017;27:17-19.

76. Goodman BP, Gupta F. Defining successful treatment of neurogenic orthostatic hypotension with droxidopa in a patient with multiple system atrophy. Clin Auton Res 2017;27:21-23. [PubMed: 28631222] 
77. Gupta F, Kremens D, Vernino S, Karabin B. Managing neurogenic orthostatic hypotension in a patient presenting with pure autonomic failure who later developed Parkinson disease. Clin Auton Res 2017;27:9-11. [PubMed: 28699048]

78. Kaufmann H, Norcliffe-Kaufmann L, Hewitt LA, Rowse GJ, White WB. Effects of the novel norepinephrine prodrug, droxidopa, on ambulatory blood pressure in patients with neurogenic orthostatic hypotension.J Am Soc Hypertens 2016;10:819-826. [PubMed: 27622314]

79. Kaufmann H, Saadia D, Voustianiouk A, et al. Norepinephrine precursor therapy in neurogenic orthostatic hypotension. Circulation 2003;108:724-728. [PubMed: 12885750]

80. Espay AJ, LeWitt PA, Kaufmann H. Norepinephrine deficiency in Parkinson's disease: the case for noradrenergic enhancement. Mov Disord 2014;29:1710-1719. [PubMed: 25297066]

81. Okamoto LE, Shibao C, Gamboa A, et al. Synergistic effect of norepinephrine transporter blockade and alpha-2 antagonism on blood pressure in autonomic failure. Hypertension 2012;59:650-6. [PubMed: 22311903]

82. Shibao C, Raj SR, Gamboa A, et al. Norepinephrine transporter blockade with atomoxetine induces hypertension in patients with impaired autonomic function. Hypertension 2007;50:47-53. [PubMed: 17515448]

83. Ramirez CE, Okamoto LE, Arnold AC, et al. Efficacy of atomoxetine versus midodrine for the treatment of orthostatic hypotension in autonomic failure. Hypertension 2014;64:1235-40. [PubMed: 25185131]

84. Shibao C, Martinez J, Palma JA, Kaufmann H, Biaggioni I. Norepinephrine levels predicts the improvement in orthostatic symptoms after atomoxetine in patients with neurogenic orthostatic hypotension (P5.320). Neurology 2017;88.

85. Palma JA, Norcliffe-Kaufmann L, Martinez J, Kaufmann H. Supine plasma NE predicts the pressor response to droxidopa in neurogenic orthostatic hypotension. Neurology 2018;91:e1539-e1544. [PubMed: 30232253]

86. Jordan J, Shibao C, Biaggioni I. Multiple system atrophy: using clinical pharmacology to reveal pathophysiology. Clin Auton Res 2015;25:53-9. [PubMed: 25757803]

87. Singer W, Sandroni P, Opfer-Gehrking TL, et al. Pyridostigmine treatment trial in neurogenic orthostatic hypotension. Arch Neurol 2006;63:513-8. [PubMed: 16476804]

88. Okamoto LE, Shibao CA, Gamboa A, et al. Synergistic Pressor Effect of Atomoxetine and Pyridostigmine in Patients With Neurogenic Orthostatic Hypotension. Hypertension 2019;73:235241. [PubMed: 30571543]

89. Fanciulli A, Jordan J, Biaggioni I, et al. Consensus statement on the definition of neurogenic supine hypertension in cardiovascular autonomic failure by the American Autonomic Society (AAS) and the European Federation of Autonomic Societies (EFAS) : Endorsed by the European Academy of Neurology (EAN) and the European Society of Hypertension (ESH). Clin Auton Res 2018;28:355-62. [PubMed: 29766366]

90. MacLean AR, Allen EV. Orthostatic hypotension and orthostatic tachycardia - Treatment with the "head-up" bed. JAMA 1940;115:2162-2167.

91. Kaufmann H, Palma JA. Neurogenic orthostatic hypotension: the very basics. Clin Auton Res 2017;27:39-43. [PubMed: 28620715]

92. Di Stefano C, Maule S. Treatment of supine hypertension in autonomic failure: a case series. Clin Auton Res 2018;28:245-246. [PubMed: 29080922] 


\section{Box 1.}

Non-pharmacological treatments for orthostatic hypotension

- Liberalization of salt consumption

- $\quad$ Liberalization of water intake (up to 2.5 liters/day)

- $\quad$ Acute water bolus (drinking $500 \mathrm{ml}$ of water)

- Sleeping with the head of the bed raised 30-45 degrees with the help of an electric bed or mattress

- $\quad$ Physical activity with recumbent exercises (stationary bicycle, rowing machine, etc.) or in a swimming pool

- $\quad$ Physical countermaneuvers (e.g., standing up slowly, leg crossing, buttock clenching $)^{49}$

- Abdominal binder ${ }^{51}$

- Compression waist-high stockings producing at least $15-20 \mathrm{mmHg}$ pressure ${ }^{50}$ (knee- or thigh-high stockings are typically not useful) 


\section{Key points:}

- $\quad$ Approximately 50\% of patients with Parkinson disease have orthostatic hypotension, although it is symptomatic in only a third of these patients.

- Orthostatic hypotension in Parkinson disease is usually neurogenic, which is due to inappropriate release of norepinephrine from sympathetic terminals when standing.

- Diagnosis of orthostatic hypotension requires blood pressure measurements. A heart rate increase below 0.5 beat per minute for each $\mathrm{mmHg}$ fall in systolic blood pressure (i.e., $\Delta \mathrm{HR} / \Delta \mathrm{SBP}$ ratio below $0.5 \mathrm{bpm} / \mathrm{mmHg}$ ) has very high sensitivity and specificity to diagnose neurogenic orthostatic hypotension.

- The goal of treatment of orthostatic hypotension is not to normalize standing blood pressure, but to reduce symptom burden to improve quality of life.

- The steps in management are: correction of aggravating factors, implementation of non-pharmacologic measures and pharmacologic therapies, including fludrocortisone, midodrine, droxidopa and norepinephrine reuptake inhibitors. 


\section{Synopsis:}

Orthostatic hypotension $(\mathrm{OH})$ is a sustained fall in blood pressure on standing which can cause symptoms of organ hypoperfusion. $\mathrm{OH}$ is associated with increased morbidity and mortality and leads to a significant number of hospital admissions particularly in the elderly. $\mathrm{OH}$ can be due to volume depletion, blood loss, cardiac pump failure, large varicose veins, medications, or due to defective activation of sympathetic nerves and reduced norepinephrine release upon standing (i.e., neurogenic $\mathrm{OH}$ ). Neurogenic $\mathrm{OH}$ is a frequent and disabling problem in patients with synucleinopathies such as Parkinson disease, multiple system atrophy, and pure autonomic failure, and is commonly associated with supine hypertension. Several pharmacologic and non-pharmacologic therapeutic options are available. Here we review the epidemiology, diagnosis, and management of neurogenic $\mathrm{OH}$, and provide an algorithm for its treatment emphasizing the importance of removing aggravating factors, implementing non-pharmacologic measures, and selecting appropriate pharmacologic treatments. 

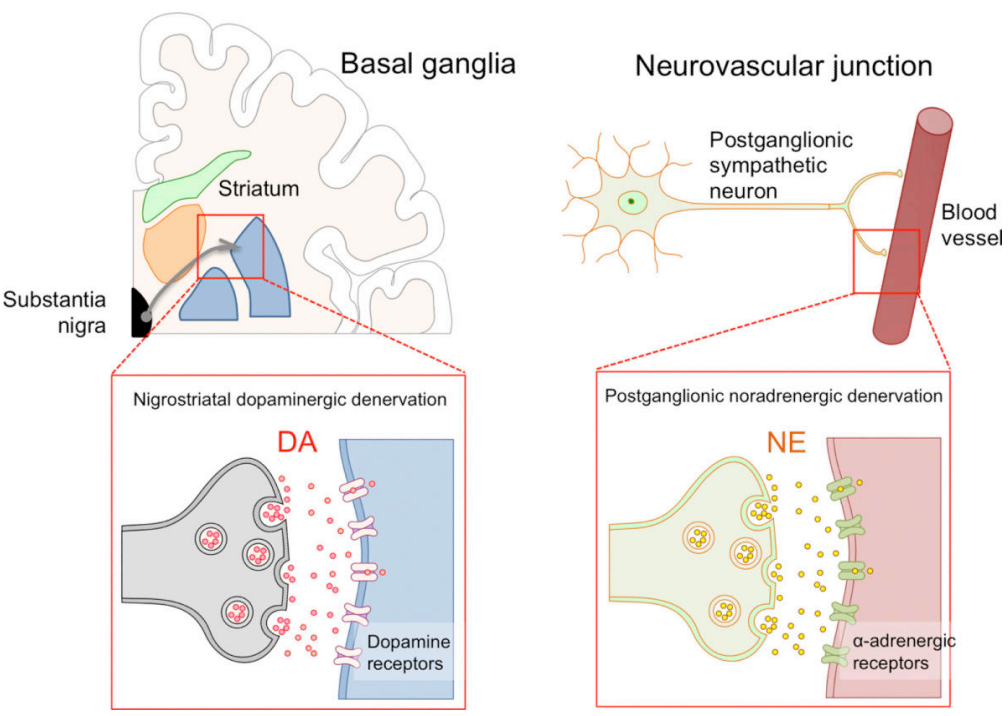

Figure 1. Neurotransmitter disorders in Parkinson disease.

Neurogenic orthostatic hypotension can be understood as a neurotransmitter disorder, similar to the motor dysfunction. Nigrostriatal dopaminergic denervation causing defective dopamine (DA) release results in the movement disorder, whereas postganglionic sympathetic denervation causing defective norepinephrine (NE) release when standing causes neurogenic orthostatic hypotension. 
Table 1.

Distinauishina features of neurosenic and non-neurosenic orthostatic hypotension

\begin{tabular}{|l|l|l|}
\hline & Non-neurogenic orthostatic hypotension & Neurogenic orthostatic hypotension \\
\hline Epidemiology & Typically elderly & Typically middle-aged \\
\hline Onset & Variable & $\begin{array}{l}\text { Usually chronic (Acute or subacute with } \\
\text { immune-mediated etiology) }\end{array}$ \\
\hline Causes & $\begin{array}{l}\text { Intravascular volume loss (e.g., dehydration, } \\
\text { anemia) Blood pooling (e.g., } \\
\text { skeletal muscle varicose veins, } \\
\text { Adrenal insufficiency Physical deconditioning } \\
\text { Antihypertensive medications }\end{array}$ & $\begin{array}{l}\text { Reduced norepinephrine release from } \\
\text { sympathetic post-ganglionic nerves when } \\
\text { standing up }\end{array}$ \\
\hline Prognosis & Resolves when underlying cause is corrected & Chronic disorder \\
\hline Sympathetic tone & Increased & Low or absent \\
\hline Increase in heart rate upon standing & Pronounced & Mild or absent \\
\hline HHR/ $\Delta$ SBP ratio & $>0.5$ bpm / mmHg & <0.5 bpm / mmHg \\
\hline $\begin{array}{l}\text { Blood pressure overshoot (phase 4) } \\
\text { in Valsalva maneuver }\end{array}$ & Present & Absent \\
\hline $\begin{array}{l}\text { Increase in plasma norepinephrine } \\
\text { levels upon standing }\end{array}$ & Normal or enhanced (at least x2) & Reduced or absent (less than x2) \\
\hline $\begin{array}{l}\text { Other symptoms of autonomic } \\
\text { failure }\end{array}$ & No & $\begin{array}{l}\text { Gastrointestinal dysfunction Urinary dysfunction } \\
\text { Sudomotor abnormalities Erectile dysfunction } \\
\text { (men) }\end{array}$ \\
\hline $\begin{array}{l}\text { Concomitant neurological deficits } \\
\text { None (or if present, they are unrelated to } \\
\text { orthostatic hypotension) }\end{array}$ & $\begin{array}{l}\text { None Parkinsonism Cerebellar signs Cognitive } \\
\text { impairment Sensory neuropathy }\end{array}$ \\
\hline
\end{tabular}

